\title{
LA CRISIS DE LA FILOXERA EN ESPAÑA SEGÚN LA REPRESENTACIÓN DIPLOMÁTICA FRANCESA*
}

\author{
Gemma Molleví Bortolo ${ }^{1}$ y David Serrano Gine ${ }^{2}$ \\ ${ }^{1}$ Chaire UNESCO "Culture et Traditions du Vin" \\ Institut Jules Guyot IUW \\ Rue Claude-Ladrey, BP 27877, Bureau 108 \\ Université de Bourgogne \\ 21078. Dijon, Francia \\ e-mail: gemografia@yahoo.es \\ 2 Servei de Gestió i Evolució del Paisatge \\ Departament de Geografia Física i Anàlisi Geogràfica Regional \\ Universitat de Barcelona \\ C/ Montalegre, 6 \\ 38001 Barcelona \\ e-mail: dserrano@ub.edu
}

\begin{abstract}
Resumen: Durante el último cuarto del siglo XIX la diplomacia francesa realizó diferentes informes sobre la situación de la vid en España. Estas reseñas se centraron en la cuestión filoxérica y comprendían diversos aspectos de esta plaga: avance territorial, técnicas de control, repercusiones sociales y económicas y consecuencias agronómicas. Las crónicas que se elaboraron se concretaron en el ámbito francés, aunque también incluían anexos con comentarios referentes a otros países. Los informes concernientes a España son de carácter diverso e irregular, si bien representan una herramienta de interés para estudiar la plaga de la filoxera en España. La temática filoxérica ha sido estudiada en profundidad, y la información que se aporta en estas páginas ha de entenderse como una fuente de documentación novedosa y complementaria a otros trabajos realizados con anterioridad.
\end{abstract}

Palabras clave: filoxera, vid, crisis agraria, diplomacia francesa.

\begin{abstract}
During the last quarter of the XIXth century, the French diplomacy did different reports about the situation of the grapevine in Spain. The information explained the pest of the phylloxera in the vineyards and her different aspects:
\end{abstract}

${ }^{1}$ Recibido: 24-04-09. Aceptado: 25-06-10. 
the advance of the disease, the social and economic techniques of control or her agrarian consequences. These reports were centered in the French regions, but also included references to other countries. The information concerning to the situation of this disease in Spain is diverse and irregular, although it represent an interest tool for study the plague of the phylloxera in Spain. It is important to know that the phylloxera question has been studied largely. For this reason, this information must be understood like a complement for the other studies realised in the agrarian history of the grapevine.

Keywords: phylloxera, grape-vine, agrarian crisis, French diplomacy.

\section{Presentación y metodología}

Uno de los aspectos bien estudiados en la historia agraria española es, sin duda, la crisis filoxérica de finales del siglo XIX. La llegada de la filoxera a Europa, su expansión por el continente y su entrada y difusión por España han sido motivo de diferentes trabajos, tanto desde el punto de vista agronómico como económico, social y ambiental; la bibliografía al respecto es extensa. Las obras de referencia acostumbran a estructurar el objeto de estudio de manera sectorial y cronológica: reseñando la situación prefiloxérica y adoptando puntos de vista territoriales, económicos, sociales o agrarios. También hay estudios agrarios generales que resaltan la importancia de la crisis filoxérica en la historia del sector agrario español (Arnabat, 2003; Carnero, 1980; Colomé, 2001).

Probablemente, uno de los trabajos más reconocidos es el del geógrafo Iglésies (1968), que se centra en Cataluña y que es precursor entre los del resto de España. Iglésies introduce el tema, describe brevemente la situación anterior a la llegada de la plaga e indica el desarrollo de la enfermedad, adoptando una perspectiva muy amplia y especialmente descriptiva. En su trabajo, recoge la iniciativa propuesta por Joan Miret para frenar la plaga, basada en el establecimiento de una zona de defensa de treinta kilómetros de largo por veinticinco de ancho en el límite oriental de los Pirineos, es decir, una franja de amortiguación que evitara el paso del insecto desde Francia. En la obra de Iglésies se citan distintas revueltas sociales, que evidencian la inquietud que despertaba la plaga en la población, se señalan los principales métodos y técnicas empleados para frenar el avance del pulgón y se incluye una reseña de las consecuencias de la enfermedad, haciendo especial hincapié en el plano social y económico. Trabajos posteriores confirman el interés por la incidencia de la enfermedad en Cataluña, como los elaborados por Giralt o los presentados durante el Congreso Histórico Internacional del Centenario de la Filoxera y el Cava, celebrado en la ciudad de Sant Sadurní d'Anoia a los cien años de la llegada de la filoxera en tierras del Penedès. 
Ejercicios similares se han desarrollado en Andalucía, donde la plaga también se dejó notar de manera cruenta. El trabajo de Zoido (1976) es uno de los pioneros, se sitúa en el ámbito onubense y presta atención a las repercusiones de la filoxera en el viñedo de Jerez. También es interesante el trabajo de Lacomba (1980), realizado para el caso malagueño y elaborado desde una perspectiva social, igual que el de Justicia y Ruiz (1987), o la obra de Pellejero (1990), en este caso desde la perspectiva de la historia económica. De la misma manera se han elaborado monografías para otras regiones españolas, como es el caso del trabajo de Piqueras para el País Valenciano (1981), de Camarero para Burgos (1989) o de Lana para Navarra (2001), por citar únicamente tres experiencias. Otras aportaciones se han centrado en relacionar los efectos filoxéricos entre distintas regiones, como es el caso de Carnero (1980) para Andalucía y Cataluña, o el de Pan-Montojo (1994) para un ámbito geográfico más amplio.

Para el conjunto español, conviene referirse a la obra de Huetz de Lemps (2009), que toma como hilo conductor la difusión espacial de la enfermedad, y señala cinco puertas de entrada de la plaga: el foco andaluz (1878), originado por la importación de plantas francesas infectadas; el foco catalán (1879) causado a partir del contacto con el viñedo francés; el foco gallego (1882) y el foco leonés (1884), ambos originados por contacto con viñedos portugueses infectados; y el foco navarro (1882), provocado por vecindad con el viñedo francés (Figura 1).

Finalmente, Piqueras (2005) ha desarrollado recientemente un estudio muy completo para España, donde resalta la relativa rapidez de la expansión de la plaga, que cifra en cuarenta y cinco años. También indica la existencia de viñedos que nunca fueron diezmados en el centro de La Mancha, en sectores de Murcia, en la meseta del Duero, en el noroeste de Orense, el sureste de Alicante, el oeste de Cádiz y en Canarias. El autor señala la entrada de la plaga en la península Ibérica por Portugal, en una finca del municipio de Gouvinhos y, más tarde, la llegada a los ya citados focos españoles de Málaga y Gerona.

El objetivo del presente artículo es dar a conocer, relacionar y constatar la información que, sobre la plaga de la filoxera, se encuentra recogida en una colección de cartas remitidas por la representación diplomática francesa en España. Para ello se sitúa el tema de estudio en un contexto general, se expone la información colectada y se coteja esta información con otras obras de aceptado reconocimiento, prestando especial atención al trabajo de Piqueras (2005), por ser la sistematización más reciente sobre el tema.

El método de trabajo seguido ha partido de una revisión exhaustiva de los fondos bibliográficos del Centre d'Études et Recherches sur la Vigne et le Vin (CERVIN). El CERVIN, situado en Burdeos, es una institución dedicada a "la investigación, la 


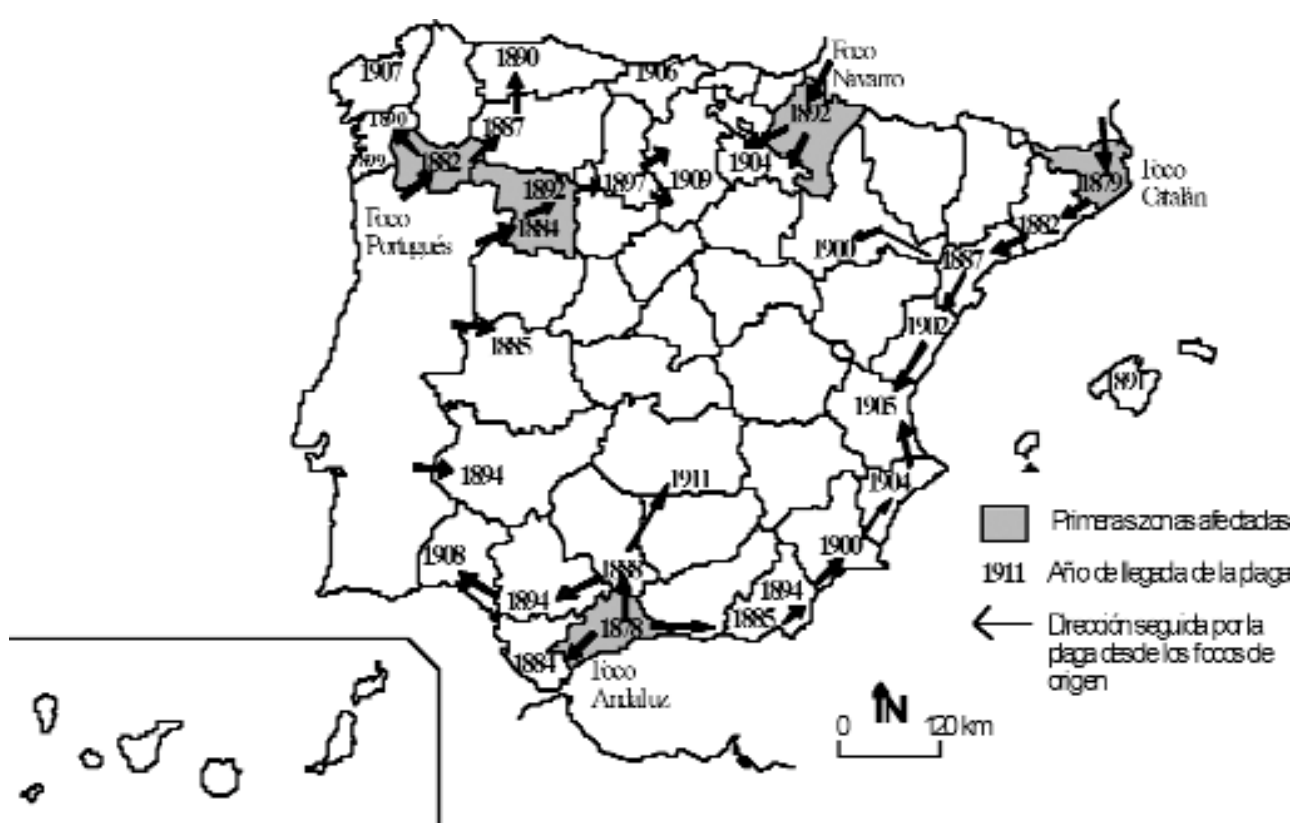

Figura 1. La entrada de la filoxera en España.

Fuente: Huetz de Lemps, 2009, Les vins d'Espagne, 149

difusión y la valorización de las ciencias humanas y sociales de la vid y el vino" con gran renombre en Francia. Sus fondos bibliográficos gozan de una consideración notable y en sus archivos se encuentran documentos aún poco explotados por la comunidad de geógrafos. El feliz hallazgo de una colección de cartas, remitidas por la diplomacia francesa durante la segunda mitad del siglo XIX, proporciona nueva información sobre la llegada y difusión de la filoxera en Europa. La singularidad de esta información es elevada, motivo por el cual debe considerase con prudencia. En algunas ocasiones proporciona datos novedosos, poco conocidos o totalmente ignorados hasta la fecha, mientras que en otras ocasiones aporta información redundante, o incluso contradictoria. Es por ello que resulta preciso dejar claro el alcance modesto de nuestra aportación, que se limita a mostrar la existencia y valor de una fuente de información poco conocida.

El método seguido se ha basado en la revisión de las 135 cartas remitidas por el cuerpo diplomático francés al Ministerio de Agricultura y Comercio entre 1878 y 1890. Del total de documentos consultados únicamente veintiséis informes fueron elaborados por diplomáticos destacados en España, en un periodo de tiempo que se inicia en 1881 y finaliza en 1890. Los informes realizados se refieren a las principales 
zonas vitícolas de la época (sureste andaluz, Levante y Cataluña), así como a enclaves con cierto interés o singularidad, como es el caso de Canarias, la cornisa cantábrica o la submeseta norte.

\section{La plaga de la filoxera: aspectos generales}

Filoxera es el nombre que se dio a un insecto de origen americano que afecta, en mayor o menor grado, a las variedades vitícolas del género Vitis. Se trata de un pulgón, endógeno de América, que fue introducido en Europa con la importación de cepas estadounidenses, y que se convirtió en el siglo XIX en una plaga para las vides europeas.

Dactylosphaera vitifoliae es un homóptero de la familia de los filoxéridos que incide sobre la vid de manera aérea y subterránea. A la forma subterránea se la conoce con el nombre de "radicícola", mientras que la aérea recibe la designación de "gallícola". La filoxera aérea forma agallas en las hojas hasta secarlas, si bien no provoca la muerte de la planta; la filoxera subterránea, en cambio, crea aberturas en las raíces de la planta, provocando infecciones que causan la muerte de la vid. Se conoce que la variante radicícola tiene dificultades para moverse por suelos arenosos; es por este motivo que los viñedos asentados sobre arenas, como por ejemplo, los de algunos pagos manchegos o del sureste alicantino, nunca llegaron a dañarse. Asimismo, conviene aclarar, que entre la infección y la muerte de una planta puede mediar un tiempo de hasta tres años. Todas estas características, unido al marcado polimorfismo del insecto, dificultaron su catalogación y estudio, de tal manera que los distintos autores que estudiaron esta enfermedad de la vid, acabaron por dar nombres diferentes a un mismo insecto. En 1854, Asa Fitch lo identificó en Estados Unidos bajo el nombre de Peritymbia vitisana; en 1868, Henri Schimer lo catalogó como Dactylosphaera vitifoliae; en 1868, Jules Émile Planchon se refirió a él como Rhizaphis vastatrix y, posteriormente, como Phylloxera vitifolii; un año más tarde, quedó catalogado con su primera designación.

A pesar de los graves daños que el pulgón provoca en la vid, la filoxera nunca ha llegado a erradicarse. Existen tres grandes tácticas que, con mayor o menor fortuna, se utilizaron para combatir la filoxera. La primera de ellas es la inmersión de viñedos, con objeto de ahogar el insecto; la segunda, la aplicación de substancias químicas en las vides y en la tierra; la tercera, el injerto de variedades europeas sobre pies de vides americanas resistentes a la filoxera. Las dos primeras medidas pretendían eliminar la enfermedad, mientras que la tercera era una solución alternativa. 


\subsection{La expansión de la filoxera}

La filoxera se convirtió en una plaga al llegar al continente europeo, pues en su región de origen no tenía calidad de pandemia. La introducción de la filoxera en Europa fue debida, en gran parte, a la imprudencia. Otras enfermedades vitícolas que afectaron a los viñedos europeos fueron el oídio y el mildiu, pero éstas no provocan la muerte de la planta, sino un debilitamiento de la vid que comporta una reducción de la cosecha. A fin de investigar y experimentar distintas formas de combatir las plagas, se trajeron vides de América a viveros ingleses y franceses; con la importación nadie se percató de que esas vides eran portadoras de filoxera (Molleví, 2007).

La difusión de la enfermedad por Europa fue desigual, en el tiempo y en el espacio. El caso más estudiado es el francés, a través de trabajos como, entre otros, el de Pouget (1990); con todo, no es fácil establecer una cronología precisa. Al parecer la filoxera llegó a Francia en 1863, afectando en primer lugar a las vides de Pujault (departamento de Gard), aunque su expansión real se inició en 1865, con la aparición de un segundo brote de infección en Crau de Chateaurenard (Bouches-duRhône). Les siguieron nuevos focos en Floirac (Gironda) en 1866 y en el triángulo del valle del Ródano, entre Cadarache al este, Castries al oeste y Tain-l'Ermitage al norte, en 1871. Al año siguiente, la plaga llegó cerca de la región vitícola de Cognac, en 1878 se extendió por Côte d’Or, en 1883 apareció en la Provenza y en 1894 en la región de Champagne. Arrasó con gran rapidez las vides francesas, especialmente durante los años de 1870. Las consecuencias de la enfermedad fueron diversas; a título de ejemplo, y para la región de Burdeos, se puede citar la obra de Hinnewinkel (2004), de carácter histórico y social.

Aparte de Francia, otras zonas fueron dañadas con más o menos rapidez, y de manera prácticamente simultánea en Centroeuropa, en la costa atlántica y en las islas mediterráneas, a las que siguieron las colonias de ultramar y las del norte de África (Ciudad del Cabo, 1880; Argelia, 1885; Túnez, 1905). Quedaron exentos de la plaga aquellos viñedos de gran aislamiento, como el chileno, o aquellos otros asentados sobre substrato arenoso. El problema filoxérico se zanjó con la llamada "solución americanista", esto es, la plantación de vides americanas resistentes a la enfermedad e injertadas con variedades locales que ofrecieran una respuesta satisfactoria. Pero esta solución se impuso básicamente por exclusión, cuando los métodos basados en la aplicación de insecticidas habían fracasado, y la mayor parte de los viñedos, o bien habían desaparecido, o bien se hallaban gravemente diezmados. De hecho, la Escuela de Agricultura de Montpellier, pionera en experimentación antifiloxérica, rechazó repetidas veces el uso de plantas americanas, puesto que no comportaban la eliminación de la enfermedad y, en efecto, únicamente constituían una solución provisional. 


\subsection{La filoxera en España}

En España se llevaron a cabo distintas iniciativas orientadas a combatir la filoxera. En 1880 se realizó el Congreso de Agricultura General y Ganadería de Madrid; unos meses más tarde se desarrolló en Zaragoza el Congreso Internacional Filoxérico, donde se concretaron aspectos relativos a la defensa de viñedos, la extinción de focos, la plantación de vides americanas y la creación de viveros de plantas resistentes. Se redactaron distintas legislaciones con objeto de frenar el avance de la plaga, aunque también se produjo cierta descoordinación y desidia entre el campesinado, los propietarios, los técnicos agrónomos y la Administración. Prueba de ello es un decreto de 10 de septiembre de 1885, que establecía la creación de cuatro estaciones enológicas (Alicante, Ciudad Real, Logroño y Zamora), todas ellas dirigidas por una estación central en Madrid, que nunca llegaron a ejecutarse por falta de medios económicos. Dichas estaciones derivan de la Ley de Enseñanza Agrícola, de 1876, que establecía instrumentos para promover la producción vegetal y animal, y también la lucha y el control de plagas (Cartañà, 2005: 229 y 241).

En la actualidad se conoce que existieron distintas propuestas para frenar el avance de la plaga, aunque muchas de ellas no llegaron a implantarse y, si lo hicieron, no tuvieron ningún éxito, de forma que el viñedo español terminó sucumbiendo al insecto. Este es el caso, por ejemplo, de una propuesta publicada el 2 de octubre de 1883 en Logroño, que tenía por intención crear un cordón antifiloxérico en el valle del Ebro. La iniciativa, sostenida por José Bellido, Antonio Oriés, Isidro Castroviejo, Julián Rivera y Amós Salvador, abogaba por la creación de una zona de aislamiento para los viñedos de Álava, Logroño, Navarra, Zaragoza y Huesca, de un mínimo de treinta kilómetros de ancho, que en algunos puntos podía duplicarse. Esta franja nacía en el Pirineo central y bajaba por los Monegros hasta alcanzar Teruel, donde enlazaba con Guadalajara y remontaba hacia Soria, Burgos y Álava, para terminar en el norte de Navarra. La iniciativa preveía que los viticultores afectados fueran compensados con cinco céntimos de peseta por decalitro de vino recolectado por año, y para ello se valoraba la producción de los últimos cinco años, excepto los de la provincia de Burgos, donde el periodo era de cuatro años a causa de la mala calidad del vino.

En la época se contaban en España siete distritos vitícolas (Jerez, Niebla, Valdepeñas, Nava del Rey, Cariñena, Priorat y Rioja), que fueron totalmente destruidos. Así, el viñedo español, salvo casos concretos, fue dado por perdido. Sólo quedaron indemnes pequeñas áreas aisladas, como en el caso del archipiélago Canario, o en lugares con condiciones edáficas no propicias al insecto, como en el caso de ciertas fincas en Valladolid, Segovia, La Mancha, Cádiz, Alicante u Orense (Piqueras, 2005). La enfermedad afectó más de un millón de hectáreas, que se destruyeron en unos cuarenta y cinco años, entre los siglos XIX y XX, a un ritmo temporal y con una distribución espacial muy heterogénea, tal como demuestra el 
Mapa de la invasión filoxérica en España basta 1899 (Figura 2), elaborado por el Ministerio de Fomento (1899).

En su topografía médica de Vilafranca del Penedès de 1899, Girona i Trius describe con gran dramatismo el panorama que, tras el paso de la plaga, existía en la región:

“... no bay un solo palmo que no esté cultivado ó que no produzca algo mas ó menos bien y mas ó menos bueno siendo el principal cultivo la viña. Pero como fuere que la filoxera esa temible plagueza que vino de las americas que tanto destrozo produjo en donde antes habia un viñedo [i?] hace algunos años de nuestros campos y destruyó destruye y acaba de destruir las hermosisimas plantaciones de viñas que eran la admiración de Vilafranca entera acabando con la vida de todas las cepas de la variedad vitis vinifera que era la que se cultivaba bizo que se llenara de panico y contaminación toda la comarca é hicimos formar una [¿?] y de [¿?] ceremonias a los

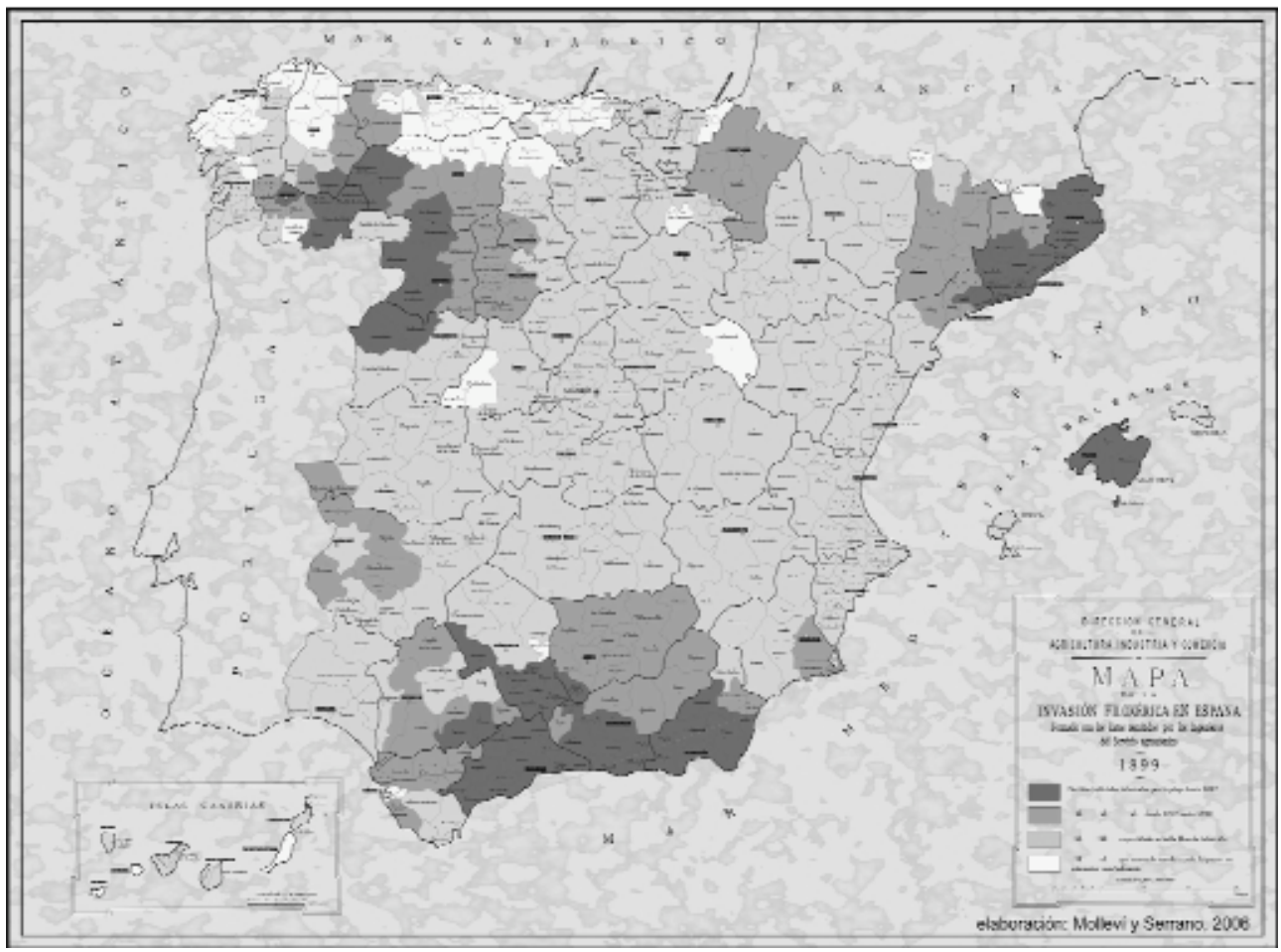

Figura 2. La invasión filoxérica en España (1899).

Fuente: Ministerio de Fomento, 1899, Mapa de la invasión filoxérica en España, hasta 1899, elaborado con los datos remitidos por los ingenieros agrónomos afectos a este servicio. 
vecinos... desde que la filoxera con su fuerza devastatriz y asoladora destruyó los viñedos de nuestros campos orgullo de los propietarios del Panades hay mucha mas aficcion y ofrega [i?] a la cria de animales que aprovechan para el trabajo consumo de sus carnes ó utilizan sus heces ó los utilizan para comerciar con ellos y sobre todo para tener con sus deyecciones abonos mas adecuados y baratos para sus campos" (Girona, 1899: s.p.).

Por su parte, el historiador Girona (1941), cuando pronunció su discurso de ingreso en la Real Academia de Ciencias y Artes de Barcelona, hizo una síntesis histórica sobre la expansión filoxérica, diferenciando cuatro periodos fundamentales en la difusión de la plaga:

a) Contra la invasión (1876-79). Caracterizado por el temor a la invasión y el estudio de métodos para imposibilitar la entrada del insecto.

b) Contra la difusión (1879-86). Marcado por la llegada del insecto y el uso de distintos métodos para evitar una mayor difusión territorial.

c) Aceptación franca de las vides americanas (1886-1892). Definido por la invasión de la filoxera tardía y la plantación de los primeros porta injertos americanos.

d) Reconstitución normal de los viñedos (a partir de 1892). Condicionado por la aceptación de la existencia de la filoxera en los viñedos y, por ello, la plantación sistemática de pies americanos.

Las consecuencias de la filoxera han sido descritas y consideradas en distintas ocasiones. Carnero (1980) ha señalado las dificultades que aparecieron en la comercialización de vinos de calidad, mientras que Pan-Montojo (1994) ha observado la especialización de regiones enteras en la producción de vinos de gama alta, como es el conocido caso de La Rioja. En algunas comarcas catalanas, la especialización vitivinícola se dirigió hacia la elaboración de vinos espumosos, especialmente en la región del Penedés (Colomé, J., 2003). Finalmente, Piqueras (2005) ha observado un cambio de cultivos, en municipios como Benicarló, Sagunto, Denia o Alicante, que sustituyeron la vid por almendros o cítricos. En otro orden de cosas, también se cita la crisis filoxérica como pretexto para la diversificación e intensificación de cultivos, la aplicación de innovaciones técnicas en la elaboración del vino, o la reglamentación del sector vitivinícola, primero, y la creación de Denominaciones de Origen, después (Molleví, 2007). La filoxera no sólo afectó al sector vitivinícola, sino que también tuvo repercusiones en el sector agrario en general, implicando la renovación del campo español al diversificar los cultivos en regiones que se habían especializado en el cultivo de la vid, en invertir el capital obtenido en la venta de vino en la agricultura, en mejorar los conocimientos de la población campesina o en aumentar la implicación de la administración en el sector a través de ayudas y reglamentaciones (Arnabat, 2003; Carnero, 1980; Colomé, 2001). 


\section{Legislación sobre la filoxera}

Para frenar la expansión filoxérica se llevaron a cabo iniciativas diversas. En el ámbito europeo destaca el Congreso de Lausana, de agosto de 1877, donde se propuso la colaboración, a escala internacional, de los distintos países vinateros de Europa. Esta asistencia tenía por objeto "ejercer, entre las diferentes naciones, una acción común, a fin de frenar, en lo posible, la expansión de la plaga en los países invadidos y de intentar preservar los lugares hasta la fecha indemnes". Los países que respondieron a la invitación de Suiza fueron seis: Alemania, Austria-Hungría, España, Francia, Italia y Portugal, reuniéndose en la ciudad de Berna el 9 de septiembre de 1878. Fruto de distintas deliberaciones, los países firmantes adoptaron la llamada Convención internacional de Berna, de 17 de septiembre de 1878, relativa a las medidas a tomar contra la filoxera (Ministère de l'Agriculture et du Commerce, 1878).

La Convención de Berna consta de siete artículos. En el artículo primero se anima a los Estados firmantes a completar su respectiva legislación, con el fin de "asegurar una acción común y eficaz contra la introducción y la propagación de la filoxera". Esta legislación hace referencia a la vigilancia de plantíos, a la delimitación de territorios afectados, a la reglamentación del transporte de vides y productos de la vid, al modo de embalaje y a la circulación de mercancías. Los artículos dos y tres se refieren al tránsito internacional de vino, uva de mesa, esquejes, sarmientos y demás productos vitivinícolas. El artículo cuatro señala la obligación de las aduanas de destruir objetos infectados y desinfectar los vehículos en que han sido transportados. En el artículo cinco se señala el compromiso de información de los estados firmantes, que deberán comunicar de manera regular la legislación dictada al respecto, las medidas tomadas, los estudios realizados, el avance de la plaga (preferentemente a través de soporte cartográfico) e información diversa que pueda resultar de interés. Los artículos seis y siete subrayan el interés internacional de la Convención, así como otra información de carácter jurídico.

Uno de los países que aplicó de manera más activa lo indicado por la Convención fue Francia. Sin duda ello se debió al papel desempeñado como primer receptor de la plaga, y también al importante peso económico del sector vitícola en ese país. El gobierno francés realizó numerosas acciones con el propósito de frenar la expansión de la filoxera. Desde el punto de vista de la legislación, es de interés la Ley de 15 de julio de 1878, relativa a las medidas a tomar tanto para frenar el avance de la filoxera como de la dorífera, una enfermedad que afectaba a las patateras. El título primero de dicha Ley se refiere a la filoxera y a los efectos que produce en la vid, mientras que el título segundo presta atención a la dorífera. En su artículo primero la Ley señala la potestad del presidente de la República para prohibir la entrada a Francia de vides, sarmientos, hojas, esquejes, abono o tutores provenientes del extranjero. El artículo dos menciona la responsabilidad del Ministerio de Agricultura y Comercio al respecto, y señala la obligación de realizar cartografías "donde se indiquen a través 
de tintas diferentes las partes del territorio atacadas por la filoxera". Los dos artículos siguientes se refieren a la constatación de la existencia y expansión de la plaga, mientras que el artículo cinco señala la existencia de subvenciones para aplicar tratamientos contra la enfermedad.

Esta misma Ley de 15 de julio, junto a un decreto de 6 de septiembre de 1878, reorganizan la estructura de la Comisión superior de la filoxera y la dotan de "carácter legal”. Esta Comisión, en realidad, ya existía con anterioridad, pero será a partir de la Ley de 15 de julio, del decreto de 6 de septiembre y de la Convención de Berna de 17 de septiembre, cuando tomará más empuje y podrá realizar la mayor parte de su actividad.

La Comisión se componía de una veintena de miembros, pertenecientes al ámbito político, académico, de agricultura y de comercio; el Ministro de Agricultura era el responsable superior directo de la Comisión. El objeto de la Comisión era "devenir guía y apoyo de la Administración en la lucha enérgica que el Gobierno ha decidido desarrollar para intentar conjurar los daños que la filoxera ha producido en la economía del país". En realidad la tarea principal de la Comisión era informar a la Administración sobre la filoxera, haciendo especial hincapié en su expansión y en las medidas necesarias para frenarla.

La Comisión recogía anualmente sus trabajos en memorias anuales que, a grandes rasgos, seguían una misma estructura. La presentación de la memoria se realizaba indicando los miembros que formaban parte de la Comisión, quienes, por lo general, se sucedían año tras año. Seguidamente se anunciaban los puntos a tratar sugeridos por el Ministro de Agricultura, así como los comentarios de interés suscitados por los miembros de la Comisión. La memoria indicaba el estado de la cuestión, y estaba complementada con documentación e información cualitativa y cuantitativa sobre el avance del insecto: los departamentos y regiones infectados, el número de hectáreas dañadas, las cooperativas agrarias que ensayaban distintos tipos de tratamientos, las subvenciones que percibían y el éxito que obtenían. La descripción de áreas infectadas se realizaba de manera sumamente minuciosa, llegando a señalarse las diferentes partidas municipales del conjunto de Francia. De esta manera, por ejemplo, sabemos que en 1878 la filoxera había destruido los viñedos de La Rochelle (departamento de Charente-Maritime) y que, sin embargo, no había hecho aparición en la vecina isla de Ré, a causa de la naturaleza arenosa del suelo.

La memoria de la Comisión se completaba con un volumen importante de documentación anexa, con datos estadísticos, informes sobre la situación de los viñedos a escala regional e informes de representantes de cooperativas agrícolas. Eventualmente también se agregaban en este apartado informes y trabajos de investigación sobre aspectos concretos de la filoxera o avances en el tema, así como 
un compendio de leyes, decretos y órdenes relativos a la plaga; en este caso la legislación se desglosaba según si correspondía a Francia, Argelia o la zona franca del País de Gex y la Alta Saboya. Finalmente, se incluía documentación cartográfica sobre el avance de la plaga: en el caso de la Francia metropolitana los mapas eran a escala 1:8.000.000, tomaban como unidad mínima de representación los distritos de cada departamento y realizaban una representación cartográfica en coropletas con una leyenda desglosada en tres niveles; en el caso de Argelia los mapas se limitaban a señalar con símbolos puntuales las áreas donde se había constatado la presencia de filoxera. En un tercer apartado de los anexos se adjuntaba información diversa sobre la filoxera en el extranjero, a partir de documentos remitidos por el cuerpo diplomático francés.

\subsection{Los informes remitidos por el cuerpo diplomático francés}

El Ministro de Agricultura solicitaba directamente al embajador, cónsul general, cónsul o vicecónsul de cada representación diplomática informes sobre el estado de la cuestión. Éstos se componían, de manera general, por una introducción al tema, una referencia a las legislaciones específicas, a la existencia y avance de la plaga, a las medidas tomadas para su combate y a las afecciones provocadas en la sociedad y la economía de cada Estado o circunscripción diplomática.

El grado de detalle de los informes es diverso. Algunos de ellos únicamente son informaciones superficiales, mientras que otros describen minuciosamente el avance de la plaga o los métodos usados para combatirla y el éxito obtenido; en ocasiones se comenta la legislación promulgada al respecto, y eventualmente se realizan traducciones al francés. En algunos informes se remite con detalle las hectáreas de viñedo existentes en cada región, la superficie afectada por la filoxera y la producción de uvas y vino, con referencias a cosechas anteriores. En otros casos se llega a incluir informes técnicos y de peritos agrícolas locales, e incluso mapas y documentos cartográficos.

La distribución por regiones de los informes es también variada. De manera global se percibe un mayor grado de información, tanto en calidad como en cantidad, a medida que avanza el tiempo. En un momento inicial los informes se circunscribieron únicamente al ámbito europeo, más cercano a Francia e indicado por la Convención de Berna. Con posterioridad se sumaron reportes de ámbitos algo más alejados, como el Imperio Otomano, Turquía, Rumania o Rusia. Finalmente, se incluyeron informes de lugares remotos, como Estados Unidos, Colonia de Victoria (Australia), Japón o República Argentina, a veces con un interesante carácter descriptivo. También se agregaron documentos de países sin vocación vitícola, pero que se posicionan respecto a la filoxera de manera clara (casos de Luxemburgo y Países Bajos). 
Para mostrar la diversidad existente se indica, sólo a título de ejemplo, los informes de dos años del periodo de estudio: en 1878 se remitieron informes de Alemania (ciudad de Metz), Italia (ciudades de Roma, Milán, Mesina y Génova) y de Suiza (Basilea); por el contrario en 1885 se remitieron informes de Alemania (Francfort, Silésia y la región del Rin y Westfalia), Austria-Hungría (reporte a nivel nacional), Bulgaria (ciudad de Roustchouk), Grecia (ciudades de Atenas, Syra y Patras), Italia (ciudades de Mesina, Cagliar, Palermo, Agrigento, Florencia, Vintimille, Nápoles, Milán, Turín, Livurno y Porto Maurizio), Portugal (ciudades de Lisboa y Porto), Rumania (informe a escala nacional), Serbia (informe a escala nacional), Imperio Otomano (Siria, Smirna, Scutari), Estados Unidos (ciudades de Filadelfia, San Francisco y Chicago) y Australia (ciudad de Melbourne), aparte de España. En total fueron veintiuno los países consultados, con un computo global de setenta y seis localidades escrutadas.

Desde España se remitieron informes en 1881 y 1882 (Málaga), 1884 (Islas Canarias, Islas Baleares, Granada, Roses, Málaga y Portbou), 1885 (Roses, Valencia y Málaga), 1886 (Barcelona, Granada, Málaga, Alicante, Cartagena y Roses), 1887 (Palma de Mallorca, Málaga y Cartagena) y 1890 (Santander, Roses, Almería, Málaga, Barcelona y Tarragona).

\subsection{Legislación española sobre la filoxera}

Como consecuencia de la filoxera, el gobierno español promulgó distintas normativas y leyes, recogidas en su mayor parte por la Junta consultiva agronómica (1899). Ante la inquietud despertada por el avance de la enfermedad en Francia, el Ministerio de Agricultura español envió en 1872 una circular informativa alertando a las provincias vitícolas. Dos años más tarde, la Ley de 21 de julio prohibía la importación de viñas de países filoxerados. El 30 de julio de 1878 se promulgó la Ley de defensa contra la filoxera y se crearon las Comisiones provinciales, que tenían por objeto la supervisión del viñedo de cada demarcación. El artículo 4 de esta ley autorizaba al Gobierno a prohibir la importación de sarmientos, cepas, árboles o arbustos susceptibles de propagar el insecto; el Decreto Real de 24 de agosto de 1878 ratificaba esta prohibición. El artículo 9 prescribía el arranque de las cepas muertas o atacadas por la filoxera, así como la desinfección del suelo. Finalmente el artículo 13 describía los presupuestos destinados por el Ministerio para realizar investigaciones sobre la filoxera y los procedimientos para combatirla.

La Dirección General de Agricultura propuso, con fecha de 18 de noviembre de 1880, una serie de medidas contra el insecto. Así, se nombraron ingenieros encargados de reconocer y limpiar los viñedos afectados, se emplearon insecticidas diversos y se crearon viveros en Málaga, Gerona, Salamanca y Zamora, entre otros 
lugares. Otro decreto, de 5 de enero de 1881, establecía la creación de viveros en las afueras de Melilla. En Decreto Real de 12 de junio de 1882 estimulaba la preocupación de las autoridades competentes y facilitaba la adquisición de insecticidas por parte del campesinado.

Con la Real Orden de 15 de diciembre de 1884 se autorizaba la importación de vides americanas para la reconstitución del viñedo, aunque esta disposición únicamente afectaba a Málaga y a Gerona. El 18 de junio de 1885 se decretaba la Ley de la defensa contra la filoxera, declarando la filoxera calamidad pública y exonerando de impuestos durante cinco años a las fincas replantadas. El 1 de septiembre de 1887 se decretó la Real Orden, la cual recordaba el cumplimiento de lo dispuesto en la ley contra la filoxera respecto a la prohibición de circulación de plantas. La Real Orden de 8 de junio de 1888 dictaba disposiciones para combatir la filoxera y ordenaba la creación de viveros de vides americanas; se acordó una subvención anual de 5.000 pesetas para las cooperativas de viticultores que reunieran, al menos, 2.000 hectáreas de viñas replantadas. El Decreto Real de 21 de agosto de 1888 creaba las comisiones itinerantes de instrucción, que se encargaban de dirigir los trabajos de destrucción del insecto, la creación de viveros y el estudio del injerto en pies americanos. En la misma época se crearon dos escuelas de ampelografía, la primera en Valencia y la segunda en Zaragoza.

El 23 de enero de 1891 se firmaba la Real Orden que autorizaba la circulación de plantas vivas, pero con condiciones que garantizaran la seguridad. El 26 de abril del año siguiente se decretaba una orden que determinaba las condiciones que habían de reunir los establecimientos dedicados al comercio de plantas, así como las épocas en que debían verificarse las visitas de inspección. La Real Orden de 17 de julio de 1893 hacía referencia a la importación de plantas, exonerando a las vides, todavía necesarias para la recuperación del viñedo. Una nueva Real Orden, de 22 de agosto de 1898 prohibía el tránsito de vides americanas por las provincias que se hallaran libres de la invasión filoxérica. Finalmente la Real Orden de 25 de enero de 1899 determinaba la forma en que habían de efectuarse las expediciones de vides americanas que tuvieran que atravesar provincias no filoxeradas. La Real Orden de 27 de febrero de 1899 ampliaba la de 25 de enero relativa al comercio de vides americanas.

\section{La filoxera en España, según la diplomacia francesa}

La expansión filoxérica en España ha sido estudiada por diferentes autores de manera laxa y desde perspectivas diversas (Girona, 1941; Huetz de Lemps, 2009; PanMontojo, 1994; Piqueras, 2005). El objetivo de este articulo, por tanto, no es redundar 
en un tema sobre el que ya se han manifestado reconocidas personalidades, sino dar a conocer una fuente documental ignorada hasta la fecha, recopilando la documentación redactada por los diplomáticos franceses ubicados en territorio español. El valor de estos informes es desigual, tanto en lo que se refiere a épocas como a lugares y a profundidad temática. En algunas ocasiones aportan datos novedosos, mientras que en otras reproducen lo anunciado por otras fuentes; también se constatan ciertas contradicciones, entre informes y respecto a lo citado en la bibliografía clásica. Todo ello implica dificultades para analizar y generalizar información aunque, al mismo tiempo, deja notar la existencia de fuentes documentales alternativas y complementarias a las ya conocidas.

\subsection{Llegada y expansión de la filoxera}

El primer informe remitido por los diplomáticos franceses ubicados en España está fechado el 14 de diciembre de 1881 en la ciudad de Málaga (Ministère de l'Agriculture et du Commerce, 1881). En la época, el viñedo malacitano ocupaba unas 65.000 hectáreas destinadas a vino, uva de mesa y, especialmente, uva pasa. Según el miembro francés destacado en ese municipio, la disposición de las vides se daba a razón de unos cuatro mil pies por hectárea en sectores llanos; en buenas condiciones esto daba de 40 a 60 hectolitros de vino por hectárea que, en relieves en pendiente, equivalía a entre 90 y 150 cajas de pasas.

A tenor del cónsul, la plaga de la filoxera apareció en la región, y por primera vez en España, en noviembre o diciembre de 1874, en la finca de la Indiana, situada a dos leguas de Málaga. Tras su llegada, la enfermedad pasó desapercibida los primeros años, si bien en 1877 eran 12 los focos filoxéricos de la región; en 1878 los puntos infectados se contaban en 132, once veces más que el año anterior; en 1879 la cifra ascendía a 1.552 focos, que ocupaban una superficie de 326 hectáreas, 66 áreas y 63 centiáreas distribuidas en un espacio total de 29.660 hectáreas. A principios del decenio la zona filoxerada aún no había alcanzado el río Guadalmedina. El 25 de mayo de 1880 la superficie perdida se cifraba en 700 hectáreas, mientras que otras 12.000 estaban afectadas en distinto grado, lo que da 52.300 hectáreas de viñedo aún indemne. De haber seguido este ritmo de progresión, la destrucción total del viñedo se hubiera producido en una veintena de años.

En 1884 se citaban en Málaga 85.000 hectáreas dedicadas a moscatel, que en 1886 se habían reducido a 62.000 hectáreas; de la superficie total de la zona norte en 1884 (28.000 hectáreas), 6.500 hectáreas estaban totalmente filoxeradas, 5.700 hectáreas parcialmente afectadas y el resto indemnes. En diciembre de 1885 el representante francés reportaba un 25,4 por ciento del viñedo destruido, un 38,5 por ciento sin producción, un 5,1 por ciento de vides gravemente atacadas, un 5,5 por ciento 
levemente afectado y un 25,6 por ciento con vides sanas. En 1887 la zona cubierta de vides en el sur de la provincia se reducía a un cordón de 50 hectáreas distribuido entre los municipios de Estepona, Coín, Ronda y Torremolinos (Ministère de l'Agriculture et du Commerce, 1884; 1890).

La dispersión de la plaga por el sur peninsular se produjo de manera irregular; los avances de la enfermedad respondían a la densidad de los viñedos y la dirección del viento. En Granada la penetración filoxérica se produjo con relativa rapidez. En 1883 la Junta de Agricultura de Granada envió una comisión de ingenieros a inspeccionar la provincia; según el diplomático francés, la campaña reveló que prácticamente todos los viñedos del litoral se encontraban atacados, si bien las partes más afectadas se encontraban en Gualchos (Castell de Ferro), Lújar y Rubite (Ministère de l'Agriculture et du Commerce, 1884). En 1886 la filoxera penetró en la Vega de Granada, destruyendo los viñedos de Santa Fé, Chauchina y Belicena, hecho que llevó a los agricultores del lugar a pedir una reducción de impuestos al gobierno.

Con un poco más de retraso la enfermedad llegó al sureste ibérico. El vicecónsul de Almería asegura que en 1887 la plaga había alcanzado Berja, municipio limítrofe con Granada. Dos años más tarde, la plaga afectaba a las localidades de Dalías, Enix, Almócita, Fondón, Alcolea, Lubrín y "ceux de la fertile contrée de l'Alpujarra" (Ministère de l'Agriculture et du Commerce, 1887; 1890).

Tras el foco andaluz aparece en España el foco catalán. La filoxera se señala por primera vez en Cataluña en 1879, al afectar a las viñas meridionales de las Alberas, entre el Pertús y Portbou y a lo largo de la frontera francesa, aunque no se manifiesta de manera evidente hasta 1881. Según el vicecónsul de Francia en Roses, en la primavera de 1882, la mitad de la provincia de Gerona estaba invadida por la plaga; ésta se extendía por el polígono limitado por el mar, las Alberas y la línea que une el Pertús, Besalú, Gerona, la Bisbal y Palafrugell. En otoño del mismo año la enfermedad se dejaba ver en el macizo de las Gavarres, al sureste de la provincia; en 1883 toda la provincia de Gerona estaba afectada, así como los municipios vecinos de Barcelona. En 1884 el vicecónsul de Roses indicaba los viñedos más afectados de la región: Roses, Cadaqués, Port de la Selva y los núcleos de Pau, Palau, Villajü̈ga, Llançà, Garriguella, Rabós, Espolla, Cantallops, Peralada y Cabanas. En 1885, cuatro quintas partes del viñedo de Roses se daba por perdido: en la vendimia de ese mismo año se recolectó una décima parte de lo habitual. Según la representación diplomática en Portbou, la disminución productiva de las vides, respecto un año normal, era de un 50 por ciento. De hecho, en 1881 se constató una disminución del 2 al 3 por ciento, en 1882 del 15 al 35 por ciento y en 1883 del 40 al 50 por ciento (Ministère de l'Agriculture et du Commerce, 1884; 1885; 1886; 1890).

Desde Gerona la plaga avanzó fácilmente hacia el sur. El cónsul en Barcelona informaba la situación en su demarcación en 1889, subrayando una invasión de este 
a oeste: el primer foco infectado se constata el 17 de octubre de 1882 en Tordera, y en 1886 la infección se había extendido de Gerona a Barcelona a lo largo de toda la costa. Ese mismo año una comisión constituida por la sociedad Fomento de la Producción Española, realizó una inspección que reveló la presencia del insecto en los viñedos de los municipios de Horta y Sant Andreu. En 1887 se constituyó la Comisión Provincial de Defensa, a partir de la Ley de 18 de junio de 1885, descubriéndose la infección de viñedos hasta el límite con Tarragona. En 1889 se encontraron trazas filoxéricas en Vilafranca y Vilanova i la Geltrú, que hasta entonces estaban consideradas indemnes. Los viñedos enfermos conforman, en este momento, una superficie homogénea hasta el límite administrativo con Tarragona (Cuadro 1) (Ministère de l'Agriculture et du Commerce, 1884; 1886; 1890).

El avance de la plaga fue rápido. El vicecónsul de Tarragona indicaba la realización de una inspección minuciosa en el límite provincial de Tarragona y Barcelona el día 16 de noviembre de 1888, bajo la organización del ingeniero agrónomo Gorria y con objeto de barrer el límite administrativo de las dos provincias en una franja de 10 kilómetros de ancho por 48 kilómetros de largo. En total se inspeccionaron los siguientes municipios: L'Arbós, Bellvei, Banyeres, Calafell, Cunit, Florens, Montmell, Santa Coloma de Queralt y Sant Jaume dels Domenys. No se encontraron indicios de la enfermedad en ningún término, excepto en L'Arbós y en Sant Jaume dels Domenys; en este último municipio los focos de infección no distaban de entre sí más de 300 metros (Cuadro 2).

Tabla 1. Afectación de la filoxera en la provincia de Barcelona (1889).

\begin{tabular}{|l|c|c|c|c|}
\hline Municipios & $\begin{array}{c}\text { Viñedos } \\
\text { infectados }\end{array}$ & $\begin{array}{c}\text { Superficie de } \\
\text { los viñedos } \\
\text { (ha) }\end{array}$ & $\begin{array}{c}\text { Superficie } \\
\text { filoxerada de los } \\
\text { viñedos (ha) }\end{array}$ & $\begin{array}{c}\text { Superficie } \\
\text { completamente } \\
\text { destruida (ha) }\end{array}$ \\
\hline $\begin{array}{l}\text { Arenys de Mar } \\
\text { Cercanías de }\end{array}$ & 23 & 4,832 & 1,258 & 357 \\
Barcelona & 11 & 3,231 & 97 & 15 \\
Granollers & 13 & 4,280 & 299 & 49 \\
Igualada & 5 & 6,721 & 116 & 16 \\
Mataró & 16 & 7,429 & 74 & 9 \\
Manresa & 3 & 4,002 & 26 & 7 \\
Sabadell & 8 & 6,292 & 252 & 36 \\
Sant Feliu & 11 & 7,427 & 186 & 17 \\
de Llobregat & 4 & 6,383 & 83 & 9 \\
Terrassa & 10 & 10,694 & 80 & 10 \\
Vilafranca & 1 & 275 & 2 & - \\
Vilanova i & & & & \\
la Geltrú & & & & \\
\hline
\end{tabular}

Fuente: Ministère de l'Agriculture et du Commerce (1890) Commission supérieure du phylloxera. Session de 1890. 
Tabla 2. Afectación de la filoxera en la provincia de Tarragona (1888)

\begin{tabular}{|l|l|c|c|c|}
\hline \multirow{2}{*}{ Municipios } & \multirow{2}{*}{ Viñas } & \multicolumn{3}{|c|}{ Superfícies filoxeradas } \\
\cline { 3 - 5 } & & $h a$. & $a$. & $c t$. \\
\hline \multirow{4}{*}{ Arbós } & la Casilla & - & 73 & 45 \\
& la Basa & - & 60 & 8 \\
& la Sermada & - & 88 & 34 \\
Sant Jaume dels Domenys & el Parillo & 2 & 17 & 97 \\
\hline
\end{tabular}

Fuente: Ministère de l'Agriculture et du Commerce (1890) Commission supérieure du phylloxera. Session de 1890

En otros lugares también se realizaron comisiones de inspección. Es el caso de las Baleares, donde a finales de septiembre de 1884 se constituyó una comisión técnica para el escrutinio de los viñedos de la isla de Mallorca. El cónsul de Francia en las islas dejó constancia de que la comisión estaba compuesta por tres miembros: el señor Paulin Vernières, viticultor francés afincado en la isla; el señor de Parotes, ingeniero agrícola de la provincia y el señor Pedro Estebrich, profesor de botánica en el Instituto Provincial. La comisión finalizó sus trabajos sin encontrar indicios filoxéricos en la isla (Ministère de l'Agriculture et du Commerce, 1887).

Por otra parte, en el foco norte, el personal destacado en Santander notificaba la situación de su circunscripción consular, que comprendía parte de la fachada atlántica y cantábrica, y provincias de la submeseta norte. Así, desde 1882, se constataba la infección de diferentes viñedos de Orense, especialmente en los núcleos de Verín, Monterrei, Oimbra y Vilardecervos, así como en las riberas del río Sil y la zona de Val de Orras. Los focos distaban entre sí de 50 a 60 kilómetros, y eran vecinos de la región portuguesa de Tras-os-Montes; en las cercanías de la capital, con todo, no se encontraron campos afectados (Ministère de l'Agriculture et du Commerce, 1890).

La plaga llegó a León en 1884 ó 1885, pero no se extendió hasta dos años más tarde; entonces los focos infectados se localizaron en los límites con Orense, en un espacio de 30 a 35 hectáreas; en 1887 se constató la presencia del insecto en algunas cepas de Salamanca, pero con poca agresividad. En esta provincia los terrenos cultivados de vides alcanzaban las 15.759 hectáreas, con un rendimiento medio de 125.000 hectolitros de vino.

En 1888 no se tenía noticia de la presencia del insecto en La Coruña, Pontevedra, Lugo, Santander y Zamora; la proporción de vides en esta zona era relativamente baja, cosa que podría explicar las dificultades en la expansión de la plaga. En La Coruña se contaban con 230 hectáreas de vides, en Pontevedra 5.343 hectáreas, en Lugo 2.680 hectáreas y en Santander 1.320 hectáreas; en Zamora, sin embargo, constaban 60.454 hectáreas, que producían de promedio 874.838 hectolitros de vino anuales. 


\subsection{Medidas tomadas}

Ante la invasión filoxérica, fueron diversas las acciones que se llevaron a cabo. En el plano legislativo, es de destacar las leyes de 30 de junio de 1878 y de 18 de noviembre de 1880. En el plano técnico, las actuaciones recurrieron al sulfato mezclado con otros productos químicos y, eventualmente, la inundación de viñedos. En general no se obtuvo demasiado éxito, motivo por el cual rápidamente se promovió la plantación de porta injertos americanos. Para su aplicación tuvo gran importancia la redacción de las leyes de 8 de junio de 1880, de 18 de junio de 1885 y de 21 de agosto de 1888; en este sentido la experiencia francesa fue de gran provecho. Los reportes redactados por los diplomáticos galos informaban sobre las distintas formas de luchar contra la filoxera y, por lo común, sus textos dejan entrever cierta desidia por parte de los agricultores y algo de desinterés por parte de la Administración.

A juicio del cónsul de Málaga, las acciones para frenar la expansión de la filoxera no fueron especialmente relevantes. En general, se nota cierto desconocimiento sobre el tema, así como incapacidad de actuación, tanto por parte del campesinado como de la Administración:

"On se bornera uniquement à constater que les pratiques tolérées par les commissions spéciales auraient été de nature à favoriser la diffusion du fléau, plutôt qu'à l'entraver. Ainsi on a vu des paysans transporter de pont en point, sous prétexte d'expériences, des fagots de sarments arrachés comme incontestablement infestés" (Ministère de l'Agriculture et du Commerce, 1881: 329).

El personal destacado en Granada, por su parte, indicaba que el insecticida más utilizado era el sulfato de carbono. La aplicación del sulfato se realizaba levantando cierta cantidad de tierra alrededor de la vid, mientras, a una distancia de 0,20-0,25 centímetros, se hacían dos agujeros de medio metro de profundidad, en los que se metían de 25 a 35 gramos de sulfato. El agujero se tapaba a fin de evitar la evaporación del producto. Este método tuvo poco éxito, según el diplomático, a causa de la naturaleza arcillosa del terreno, pues su carácter impermeable evitaba la absorción del producto. El vicecónsul añade que, en ocasiones, murieron plantas sanas por superarse las dosis máximas de sulfato. En la Vega de Granada se realizaron algunas experiencias de inmersión de viñas (Ministère de l'Agriculture et du Commerce, 1884).

En la región de Roses los medios utilizados fueron el sulfato de carbono y diferentes sulfatos alcalinos, de elevado coste. Según el representante francés, también se emplearon restos de prensado de aceituna, con resultados inciertos. La inmersión en agua de los campos de vides fue de difícil aplicación, y únicamente se ensayó en Torroella de Montgrí; aún y así se hizo observar el potencial de viñedos situados en las riberas de los ríos Muga y Ter. 
El informe consular de Barcelona indicaba que las dosis de sulfato de carbono eran de 340 a 400 gramos por metro cuadrado. El representante de Tarragona, por su parte, señalaba que cuando las cepas morían, se cortaban a ras de suelo y se rociaban con 350 gramos de sulfato, que se reducía a 30 gramos por metro cuadrado en los campos vecinos a la zona infectada, esto es, una franja de 20 metros alrededor del perímetro dañada. En realidad estas prácticas no dejaban de ser la aplicación de lo dispuesto por la Ley de 30 de julio de 1878. El representante de Roses dejaba entrever cierta decepción del campesinado hacia la Administración, quien terminará reclamando mayores niveles de formación para velar correctamente por sus viñedos (Ministère de l'Agriculture et du Commerce, 1886). Según Galet, propietario catalán entrevistado en 1886:

"Ce qui manque dans l'Ampourdan, c'est un centre de viticulteurs instruits qui, par leurs études, leurs expériences, puissent éclairer la population rurale et lui servir de guide dans le problème difficile de la reconstitution de nos vignobles détruits par le fléau du phylloxera" (Ministère de l'Agriculture et du Commerce, 1886: s.p.).

En Canarias, sin indicios de filoxera, se extremaron las precauciones con la entrada de mercancías. El cónsul francés indicó la aplicación de la Ley de 31 de julio de 1879, que prohibía la introducción total de sarmientos y plantas que, por lo común, se abastecían desde Madeira, Burdeos y Ciudad del Cabo. El representante aseveraba que, desde la primavera de 1884, las importaciones de caña de azúcar para su manufactura en las industrias insulares eran muy controladas. En efecto, en una carta fechada el 4 de septiembre de 1884, se afirmaba que cuando se intervenía una partida de caña sospechosa, rápidamente se quemaba; así se hizo con una carga proveniente de Madeira, isla que sí se encontraba filoxerada. Pero el cónsul francés subrayaba la ausencia de filoxera en las islas, siendo el oídio la única plaga que afectaba a la vid; para luchar contra ésta, las plantas eran sulfatadas con azufre, práctica que resultaba muy costosa (Ministère de l'Agriculture et du Commerce, 1884). Al parecer, este producto fue especialmente utilizado en los viñedos de Tenerife, en general, y del valle de la Orotava, en particular, puesto que la cercanía del Teide facilitaba la obtención de azufre.

\subsection{Restitución del viñedo}

Cuando el desastre tuvo lugar, se propusieron distintas alternativas al cultivo de la vid. En el sur peninsular se sugirió la caña de azúcar, habitual en la Vega de Málaga y cultivo tradicional en municipios como Motril y Salobreña. Igualmente, se propuso el cultivo de moreras para la cría de gusanos de seda, práctica típica pero en desuso en la Alpujarra (Ministère de l'Agriculture et du Commerce, 1881). 
En Málaga la reconstitución del viñedo fue lenta. En noviembre de 1884 los pies americanos plantados se contaban en unos 805.705, repartidos en nueve municipios y ochenta y dos propietarios. A razón de 4.000 pies por hectárea, eran casi 200 las hectáreas replantadas. En 1889 no eran más de 12.000 las hectáreas recuperadas (Ministère de l'Agriculture et du Commerce, 1890). En Granada se plantaron vides americanas del tipo Jacquez y de Herbemont que, a partir de experiencias realizadas en Barcelona, se adaptaban fácilmente; en opinión del vicecónsul, la población se mostraba optimista con las nuevas plantaciones. En Barcelona se crearon distintos viveros, que distribuyeron pies americanos gratuitamente entre los pequeños propietarios de la región.

El diplomático de Roses indica que las especies más utilizadas en su distrito eran Riparia y Jacquez. Asimismo, señala que los viñedos replantados se encontraban, principalmente, en Castelló d'Empúries, Llançà, Port de la Selva, Villajuïga y Villamaniscle. El representante de Portbou subrayaba que, a pesar de que la importación de pies de Francia estaba prohibida, los lugareños realizaban contrabando de porta injertos. La diplomacia francesa afirmaba que un súbdito galo del departamento de Aude, afincado en Figueres, se dedicaba a la venta de cepas resistentes a la filoxera; las variedades que vendía eran la Jacquez, muy apreciada en la región por su vitalidad, y la Riparia, de poco éxito en terrenos calizos pero de fácil adaptación en terrenos ligeros. Según el mismo informe, para los terrenos calizos se habían obtenido buenos resultados con la variedad York-Madeira. De la misma forma se señaló que, en 1884 y 1885, el vivero de Castelló d'Empúries produjo cerca de 500.000 plantas, destinadas a la replantación de pagos filoxerados. (Ministère de l'Agriculture et du Commerce, 1886).

\subsection{Producción}

Es interesante hacer mención a datos de producción y comercialización, por bien que la comparación de esta información pueda ser dificultosa. En general, hay consenso en la opinión de que los viñedos españoles, en el momento de la llegada de la plaga, gozaban de una gran vitalidad, a causa de la dilatada plantación de vides pocos años antes de la llegada de la enfermedad. Un gran número de autores señalan esta euforia vitícola, en gran parte motivada por el hundimiento de la producción vitivinícola francesa, como ya hemos comentado anteriormente. En una carta de 1884 el cónsul en Palma de Mallorca se refería a ello como sigue:

"... depuis cinq années entrâ̂nait dangereusement bon nombre de propiétaires à planter sans mesure et même à arracher olviers, amandiers, pour imiter le voisin qui plantait..." (Ministère de l'Agriculture et du Commerce, 1884: s.p.). 
Es interesante comentar el caso de Murcia, donde la plantación de vides se mantuvo constante entre 1885 y 1886, si bien la producción de vino aumentó de manera notable. Según datos del cónsul en Cartagena, en 1880 había en la provincia 22.000 hectáreas de vid, mientras que en 1885-1886 esta cifra ascendía a 32.660 hectáreas en plena producción. Entre 1885 y 1886 se cuenta un aumento de más de 60.000 hectolitros de vino (Cuadro 3). En la región, las vides se plantaban en agujeros de 70 centímetros, a distancias de 1,8 a 2 metros. Las plantas se podaban a 15 ó 20 centímetros y se dejaban cinco o seis yemas, en una operación que acostumbraba a realizarse de febrero a marzo. El resultado era un vino de coloración viva y brillante, de 14 a 16 grados (Ministère de l'Agriculture et du Commerce, 1887).

El cónsul en Valencia destacaba la atención con la que se cultivaban los viñedos "ces champs sont entretenus avec le plus grand soin" (de l'Agriculture et du Commerce, 1885: s.p.), y aseveraba que el rendimiento de la viña se triplicó entre 1875 y 1885, alcanzando el millón y medio de hectolitros de vino exportados, por valor de 27 millones de francos. Los vinos que en 1875 se vendían a 8-10 francos el hectolitro en 1885 se vendían ahora a $15-25$ y puntualmente a 30-32, a causa de la especulación del momento; los destinos principales eran Francia (que tomaba dos tercios de la producción), Estados Unidos e Inglaterra. En 1886 el vicecónsul de Alicante informaba de que el precio del vino se fijaba en 30-32 francos el hectolitro para caldos de 13 a 14 grados.

En 1887 el informe del cónsul en Palma de Mallorca indicaba una producción de cerca de 700.000 hectolitros en todo el archipiélago. En Mallorca y Menorca los vinos se definían como fuertes y de sabor áspero, ricos en color; los vinos de mayor renombre eran la malvasía de Banyalbufar, a partir de uvas Papayol rosado; el vino de Benisalem, a partir de uvas Gorgollosa; los vinos del sureste de Mallorca, Manacor,

Tabla 3. Producción vitícola en Murcia (1885-1886).

\begin{tabular}{|l|c|c|c|c|}
\hline Municipio & \multicolumn{2}{|c|}{ Superficie de vides (hectáreas) } & \multicolumn{2}{c|}{ Producción de vino (hectolitros) } \\
\hline & 1885 & 1886 & 1885 & 1886 \\
\hline Caravaca & 2.572 & 2.572 & 1.424 & 2.136 \\
Cartagena & 1.859 & 1.859 & $10.153,5$ & $15.230,25$ \\
Cieza & 1.004 & 1.004 & $14.325,6$ & $21.488,4$ \\
La Unión & 36 & 36 & 8,31 & 12,47 \\
Lorca & 951 & 951 & 560 & 840 \\
Mula & 2.348 & 2.348 & $35.641,64$ & $53.462,4$ \\
Murcia & 2.094 & 2.094 & 10.922 & 16.383 \\
Totana & 296 & 296 & 36 & 540 \\
Yecla & 21.500 & 21.500 & 48.000 & 72.000 \\
\hline
\end{tabular}

Fuente: Ministère de l'Agriculture et du Commerce (1887) Commission supérieure du phylloxera. Session de 1887. 
Felanitx y Porreres, flojos pero abundantes; y los llamados vinos "de cuarta clase", de consumo doméstico. Se conoce que los vinos de Baleares tenían fama de ser de alta graduación, motivo por el cual era habitual destinarlos a destilados.

En otros lugares el aumento de producción se debía a prácticas más avispadas, como la adulteración de caldos. El diplomático de Roses cuenta el caso tipo de un negociante que compraba una carga de uvas de 12.600 kilogramos que, tras la fermentación, se convertían en unos 78 hectolitros de vino, de unos 13 grados. Al poso restante, que contenía aún un 10 por ciento de vino, se le añadía una proporción de agua y, después del tratamiento apropiado, producía cerca de 14 hectolitros de vino de 7 a 8 grados, que se acostumbraba a mezclar con aguardiente alemán, de 15 grados (Ministère de l'Agriculture et du Commerce, 1884).

\section{Resultados y consideraciones finales}

Los informes sobre la filoxera realizados por la diplomacia francesa constituyen una fuente de información distinta y complementaria a la bibliografía tradicional. Su interés ha de considerarse de manera relativa, tanto en lo referido a temporalidad como a territorialidad, originalidad y calidad de la información. Aún y así, creemos, los atestados poseen interés, quizás no por reportar una cantidad elevada de información inédita, sino más bien por confirmar tendencias y corroborar explicaciones anunciadas en otras ocasiones.

Una de las primeras apreciaciones que conviene realizar sobre los informes, se refiere a su alcance espacial. Las cartas remitidas por la diplomacia se localizan en las siguientes regiones y ámbitos espaciales: Andalucía, Baleares, Canarias, Cataluña, Murcia, País Valenciano, suroeste y noroeste español. Se trata, pues, de una representación reducida y sesgada de España, que no contempla el centro y el norte peninsular, que obvia la afección del viñedo "nuevo" de Tierra de Barros y de otros pagos extremeños y que, en la práctica, termina centrándose en ciertas regiones del litoral mediterráneo. Así, el noroeste es referido de manera muy sutil desde un corresponsal afincado en Santander y, posiblemente, con pocos vínculos con Galicia y con la Meseta; también pasan desapercibidos sectores importantes del interior de Andalucía.

El alcance temporal de la correspondencia tampoco es muy amplio, pues apenas alcanza doce años concentrados en ocho informes, el último de los cuales data de 1890. Se obvian, así, cuatro décadas en las que el insecto continuó expandiéndose por campos aún indemnes. Este es el caso del viñedo de la depresión media y alta del Ebro y, particularmente, de Navarra, donde la enfermedad se difundió de manera 
muy rápida, entre los dos lustros que bordean el cambio de siglo (cuestión detalladamente estudiada por Lana, 2001); o el de los viñedos de Cádiz y Huelva, donde la enfermedad alcanzó su apogeo en los últimos años del siglo (tal como explica Zoido en un trabajo pionero fechado en 1976); o aún en Baleares donde apareció en 1891, entre cuyas fincas devastadas se encontraba la implantada por la familia Feliu en la isla de Cabrera, una de las más extensas y prósperas de Baleares.

En algunos casos la labor de los diplomáticos franceses se centraba en realizar síntesis de lo anunciado por la Administración y los medios de comunicación de la época. En otros casos la labor era mucho más completa, e incluía trabajo de campo y valoraciones fundamentadas. Así se puede deducir de los trabajos del cónsul de Málaga, recogidos por Vera y López (1882); de las aportaciones del delegado en Cartagena, que señala algunos municipios murcianos que duplican la producción de vino; o de los informes que recopilan los precios por hectolitro para distintas regiones. Asimismo, se reflejan informaciones puntuales, como la adulteración del vino en Roses o la existencia de comerciantes franceses en Figueres.

Finalmente, y en otro orden de cosas, hay que mencionar ciertas irregularidades de los atestados, que podrían conducir a error. Es el caso de los volúmenes de exportación citados para Valencia, que merecen matizarse pues, como apunta Piqueras (1985), una porción muy importante de la exportación española se hizo a través de puertos valencianos: esto se dio particularmente en el periodo 1890-1891, fechas en las que las expediciones desde el País Valenciano significaban en torno a la mitad de la producción española.

\section{Agradecimientos}

Este trabajo ha sido posible gracias a la financiación de la Secretaría de Estado de Universidades e Investigación del Ministerio de Educación y Ciencia y de la Generalitat de Catalunya. Los autores agradecen especialmente el apoyo y las aportaciones ofrecidas por los Doctores Jean-Claude Hinnewinkel y Phillippe Roudié miembros del Centre d'Étude et Recherche sur la Vigne et le Vin (Université de Bordeaux 3) y por los señores Nicole y Guy Mainet. También conviene agradecer las facilidades ofrecidas por el Institut Cartogràfic de Catalunya, que ha permitido el acceso al Mapa de la Dirección General de Agricultura, Industria y Comercio (escala 1:2.000.000), del Ministerio de Fomento (1899). 


\section{Bibliografía}

Arnabat, R. (2003). El sector vitivinícola a la segona meitat del segle XIX i primers anys del segle XX. En Colomé Ferrer, J. (coord) De l'Aiguardent al Cava. El procés d'especialització vitivinícola a les comarques del Penedès-Garraf. Barcelona, El 3 de Vuit i Ramon Nadal editor, p. 95-111.

Camarero, C. (1989). La filoxera en la provincia de Burgos. Estudios geográficos, 197, 531-552.

Carnero, T. (1980). Expansión vinícola y atraso agrario. La viticultura española durante la gran depresión (1870-1900). Madrid, Servicio de publicaciones agrarias, Secretaría general técnica, Ministerio de Agricultura.

Cartañà, J. (2005). Agronomía e ingenieros agrónomos en la España del siglo XIX. Barcelona, Ediciones del Serbal.

Colomé Ferrer, J. (2001). El sector vitícola español durante la segunda mitad del siglo XIX y el primer tercio del XX: el impacto de la demanda francesa, la crisis ecológica y el cambio técnico. En Carmona, J., Colomé, J., Pan-Montojo, J. y Simpson, J. (eds) Viñas bodegas y mercados. El cambio técnico en la vitivinicultura española, 1850-1936. Zaragoza, Prensas Universitarias de Zaragoza, p. 39-59.

Colomé Ferrer, J. (coord) (2003). De l'Aiguardent al Cava. El procés d'especialització vitivinícola a les comarques del Penedès-Garraf. Barcelona, El 3 de Vuit i Ramon Nadal editor, 323 p.

Girona i Trius, J. (1989). Topografía médica de Vilafranca del Panadés, 1899. Barcelona, Reial Acadèmia de Medicina de Barcelona [Documento manuscrito].

Girona, P.J. (1941). La invasión filoxérica en España. En Real Academia de Ciencias y
Artes de Barcelona. Memorias de la Real Academia de Ciencias y Artes de Barcelona, Barcelona, Real Academia, p. 153-259.

Hinnewinkel, J.-C. (2004). Les terroirs viticoles: origines et devenirs. Bordeaux, Féret.

Huetz de Lemps, A. (2009). Les vins d'Espagne. Bordeaux, Presses universitaires de Bordeaux.

Iglésies, J. (1968) La crisi agrària de 1879/1900: La fil-loxera a Catalunya. Barcelona, Edicions 62.

Justicia, A.; Ruiz, J. D. (1987). Especialización agrícola y desarticulación del espacio. La viticultura en Málaga durante el siglo XIX. Málaga, Diputación Provincial.

Lacomba, J. A. (1980). La filoxera en Málaga. Agricultura y sociedad, 16, 323-370.

Lana, J. M. (2001). Progresos y regresos de la vitivinicultura navarra. La acción pública y sus contextos sociales (1850-1936). En Carmona, J., et al. (eds). Viñas, bodegas y mercados: el cambio técnico en la vitivinicultura española, 1850-1936, Zaragoza, Prensas Universitarias, p. 275-299.

Ministère de l'Agriculture et du Commerce (1878). Commission supérieure du phylloxera. Session de 1878. Paris, Ministère de l'Agriculture et du Commerce.

Ministère de l'Agriculture et du Commerce (1881). Commission supérieure du phylloxera. Session de 1881. Paris, Ministère de l'Agriculture et du Commerce.

Ministère de l'Agriculture et du Commerce (1882). Commission supérieure du phylloxera. Session de 1882. Paris, Ministère de l'Agriculture et du Commerce.

Ministère de l'Agriculture et du Commerce (1884). Commission supérieure du phyl- 
loxera. Session de 1884. Paris, Ministère de l'Agriculture et du Commerce.

Ministère de l'Agriculture et du Commerce (1885). Commission supérieure du phylloxera. Session de 1885. Paris, Ministère de l'Agriculture et du Commerce.

Ministère de l'Agriculture et du Commerce (1886). Commission supérieure $d u$ phylloxera. Session de 1886. Paris, Ministère de l'Agriculture et du Commerce.

Ministère de l'Agriculture et du Commerce (1887). Commission supérieure du phylloxera. Session de 1887. Paris, Ministère de l'Agriculture et du Commerce.

Ministère de l'Agriculture et du Commerce (1890). Commission supérieure du phylloxera. Session de 1890. Paris, Ministère de l'Agriculture et du Commerce.

Ministerio de Fomento (1899). Mapa de la invasión filoxérica en España, hasta 1899, formado con los datos remitidos por los ingenieros agrónomos afectos a este servicio. Madrid, Dirección General de Agricultura, Industria y Comercio.

Molleví, G. (2007). La geografía de la vid y el vino en Cataluña. Barcelona, Davinci Continental, p. 49-76.
Pan-Montojo, J. (1994). La bodega del mundo. La vid y el vino en España (1800-1936). Madrid, Alianza Editorial, Ministerio de Agricultura, Pesca y Alimentación.

Pellejero, C. (1990). La filoxera en Málaga. Una crisis del capitalismo agrario andaluz. Málaga, Arguval.

Piqueras, J. (1981). La vid y el vino en el País Valenciano. Valencia, Institució "Alfons el Magnànim".

Piqueras, J. (1985). La agricultura valenciana de exportación y su formación histórica. Madrid, Ministerio de Agricultura Pesca y Alimentación.

Piqueras, J. (2005). La filoxera en España y su difusión espacial: 1878-1926. Cuadernos de Geografía de la Universidad de Valencia, 77, 101-136.

Pouget, R. (1990). Histoire de la lutte contre le phyloxéra de la vigne en France. París, INRA, 1990

Vera y López, V. (1882). La filoxera en Málaga Los vinos y los aceites, 12, 158-161.

Zoido, F. (1976). Contribución bibliográfica al estudio de la vitivinicultura jerezana. Archivo bispalense, 182, 81-106. 